\title{
Synthesis, Moleculer Docking and Anticancer Screening of Some Novel Tetrahydronaphthyl Thiazolyl Pyrazoles and other Related Derivatives
}

\author{
Z.M. Nofal, M.I. El-Zahar ${ }^{\#}$ and R.S. Gouhar \\ Therapeutical Chemistry Department, National Research \\ Centre, Cairo, Egypt.
}

\begin{abstract}
CONDENSATION of 5-amino-1-[4-(1,2,3,4-tetrahydronaphthalen7-yl) thiazol-2-yl]-1H-pyrazole-4-carbonitrile (3) with different reagents such as triethylorthoformate, ethyl chloroformate and/or hydroxyamine hydrochloride yielded the substituted pyrazoles 4-6. Cyclocondensation of 3 with formic acid, acetic anhydride, formamide and /or acetamide afforded the pyrimidine derivatives 8-11. Reaction of 3 with carbon disulphide, substituted isothiocynate, malononitrile, aldehydes and /or chloroacetylchloride yielded the corresponding derivatives 12-16. Also, hydrolysis of 3 with conc. sulfuric acid at different conditions gave 17 and/or 18. Docking studies of the newly prepared compounds as thymidylate synthase inhibitors have been done. Some of the newly prepared compounds were evaluated as anticancer agents against three human tumor cell lines (HCT116, HePG2, MCF7).
\end{abstract}

Keywords : Tetrahydronaphthylthiazole, Pyrazole, Pyrazolopyrimidine, Molecular docking, Anticancer screening, HCT116, HePG2 and MCF7.

Numerous compounds with biological activity have been investigated, however many of them are not suitable for the therapeutic use due to their toxic, carcinogenic and mutagenic properties. The use of chemotherapeutic drugs in cancer therapy involves the risk of the life threatening host toxicity. The search therefore continues to develop the drugs which selectively act on tumor cells ${ }^{(1,2)}$.

Various chemical and pharmaceutical activities were ascribed to 1,2,3,4tetrahydronaphthalene derivatives especially those incorporated into heterocyclic systems ${ }^{(3)}$. It has been reported that this type of compounds possesses a wide variety of biological activities such as potent anti-HIV ${ }^{(4)}$, antipoliovirus ${ }^{(5)}$, antibacterial $^{(6,7)}$, hypotensive ${ }^{(8)}$, anti-arrythmic ${ }^{(9)}$, molluscicidal ${ }^{(10)}$, antiplatelet aggregation $^{(11)}$, anxiolytic and antidepressant ${ }^{(12,13)}$ and as anticancer agents ${ }^{(14)}$.

The chemistry of 1,2,3,4-tetrahydronaphthalen-6-yl heterocycles especially those including thiazole moiety and/or nitrogen, oxygen or sulphur heterocycles such as pyrazoles, isoxazoles, thiadiazoles, pyrroles, pyridines and/or pyrimidines, has

\#Corresponding author E-mail:melzahar@hotmail.com 
been of increasing interest since many of these compounds have found useful applications as chemotherapeutic agents of promising activities especially as anticancer $^{(15,16)}$, or antimicrobial ${ }^{(17)}$ agents.

Folate metabolism is considered as an important target for the development of new anticancer agents due to its role in the biosynthesis of nucleic acid precursors $^{(18,19)}$. The inhibition of folate-dependant enzymes such as thymidylate synthase which catalyses the reductive methylation of deoxyuridylate (dUMP) to thymidylate (dTMP) has also been recognized as an interesting target for drug discovery $^{(20,21)}$. Classical antitumor agents that prevent this pathway have a disadvantage that they need an active transport mechanism to enter the cells which can cause tumor resistance if impaired ${ }^{(22,23)}$. Also, recent preclinical experiments on human liver carcinoma cell lines (HePG2) revealed that at higher doses of antifolate a loss of thymidylate synthase inhibition occurs and cytotoxic effects preserved ${ }^{(24)}$. So, a development of a new thymidylate synthase inhibitor that could be selective may be a good target for drug discovery.

Based on all these finding, the main goal of the present work was to design a new series of compounds structurally containing tetralin moiety incorporated with different heterocycles as a trial for the development of a new thymidylate synthase inhibitor that could be selective which may be a good target for drug discovery. For this target some docking of the newly synthesized compounds was done using Autodock Vina ${ }^{(25)}$. Moreover, the cytotoxic activities of ten a new selected compounds were screened against colon (HCT116), hepatocellular (HePG2) and breast (MCF7) carcinoma cell lines.

\section{Results and Discussion}

\section{Chemistry}

The synthetic approach was confined to two schemes to obtain the target compounds. Reaction of 1-(4-(1,2,3,4-tetrahydronaphthalen-7-yl) thiazol-2-yl) hydrazine (1) ${ }^{(26)}$ with ethoxymethylenemalononitrile (2) afforded the corresponding starting compound 4-cyano-5-aminopyrazole derivative 3. Condensation of 3 with either triethylorthoformate or ethyl chloroformate yielded the $N$-substituted-4cyanopyrazoles 4 and 5, respectively. Also, condensation of compound 3 with hydroxyamine hydrochloride afforded N'-hydroxy-4-carboxamidine pyrazole derivative 6 , that cyclized with triethylorthformate to give the pyrimidine derivative 7. Cyclocondensation of compound 3 with formic acid and/or acetic anhydride gave the corresponding pyrimidinone derivatives 8 and 9, respectively. While the cyclocondensation of compound 3 with formamide and /or acetamide gave the corresponding 4-amino pyrimidine derivatives 10 and 11, respectively (Scheme 1).

Egypt. J. Chem. 55, No.4 (2012) 


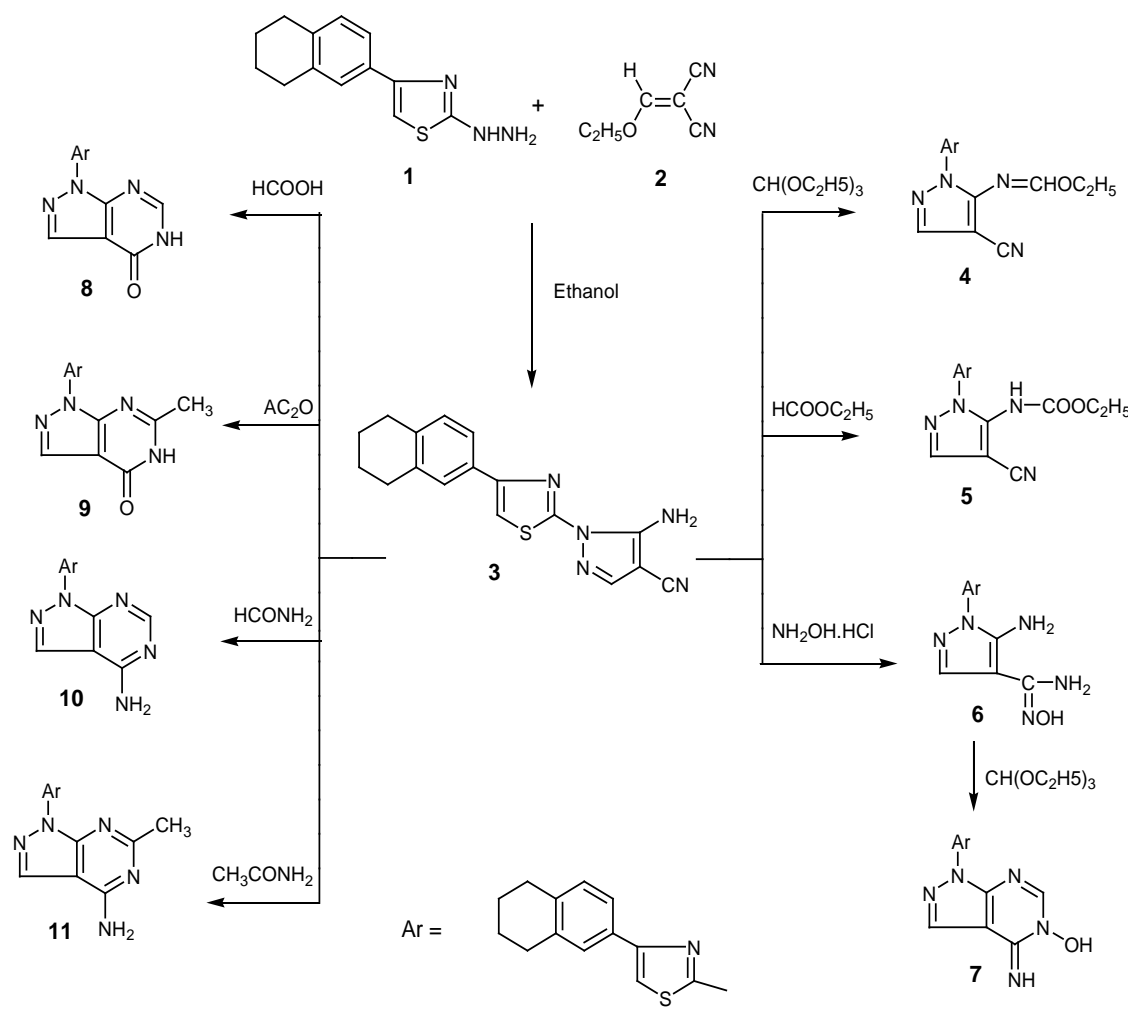

Scheme 1

On the other hand, the pyrazolo pyrimidine-dithione derivative 12 was obtained by cyclocondensation of 4-cyano-5-aminopyrazole derivative 3 with carbon disulphide in the presence of potassium hydroxide, while 4-imino-pyrazolo pyrimidine-thione derivatives 13a-d were obtained by cyclocondensation of compound 3 with isothiocynate derivatives. In addition, 4-imino-pyrazolo pyridine derivative 14 was obtained by refluxing of 3 with malononitrile in ethanol. Furthermore, condensation of derivative 3 with the appropriate aldehyde derivatives afforded the respective Schiff's bases 15a-c.

In addition, cyclocondensation of compound 3 with chloroacetylchloride yielded the pyrimidinone derivative 16 . Also, reacting compound 3 with conc. sulfuric acid at $0-5^{\circ} \mathrm{C}$ gave the corresponding carboxamide derivative 17 while the reaction at $80^{\circ} \mathrm{C}$ afforded the corresponding aminopyrazole 18 . Finally, compound 3 was reacted with diaminoethane to give the imidazolylpyrazole derivative 19 (Scheme 2). 


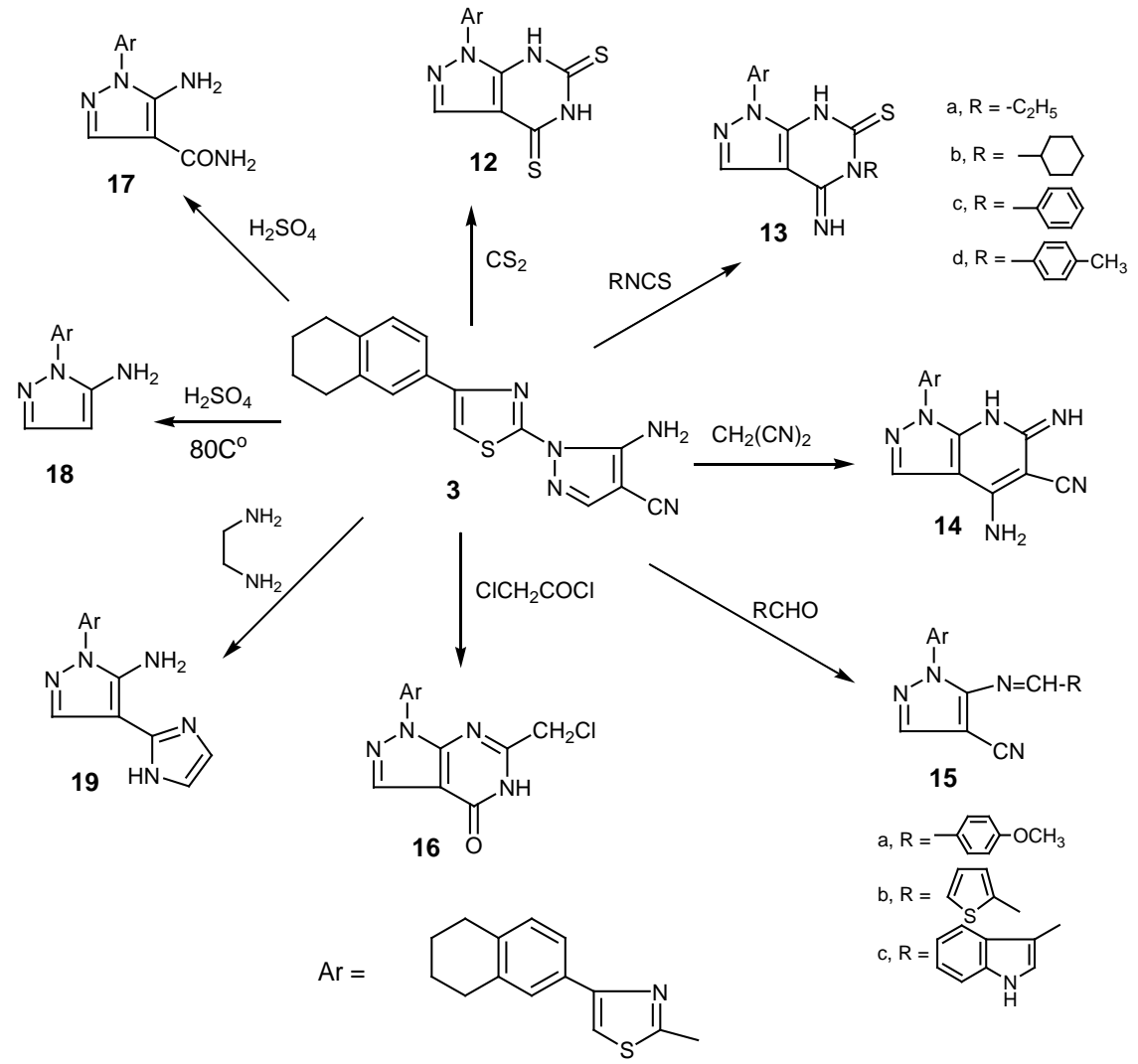

Scheme 2

Experimental

Chemistry

All melting points are uncorrected and were taken in open capillary tubes using Electrothermal apparatus 9100. Elemental microanalyses were carried out at Microanalytical Unit, Central Services Laboratory, National Research Centre, Dokki, Cairo, Egypt, using Vario Elementar and were found within $\pm 0.5 \%$ of the theoretical values. Infrared spectra were recorded on a Jasco FT/IR-6100, Fourier transform, Infrared spectrometer at $\mathrm{cm}^{-1}$ scale using $\mathrm{KBr}$ disc technique at Central Services Laboratory, National Research Centre, Dokki, Cairo, Egypt. ${ }^{1} \mathrm{H}$ NMR spectra were determined by using a JEOl EX-270 NMR spectrometer at Central Services Laboratory, National Research Centre, Dokki, Cairo, Egypt. The mass spectra were measured with a Finnigan MAT SSQ-7000 mass spectrometer at Central Services Laboratory, National Research Centre, Dokki, Cairo, Egypt. Follow up of the reactions and checking the purity of the compounds were made by TLC on silica gel-precoated aluminium sheets (Type 60, F 254, Merck, Darmstadt, Germany) and the spots were detected by exposure

Egypt. J. Chem. 55, No.4 (2012) 
to UV lamp at $\lambda_{254}$ nanometer for few seconds. The chemical names given for the prepared compounds are according to the IUPAC system.

5-Amino-1- [4-(1,2,3,4-tetrahydronaphthalen-7-yl) thiazol-2-yl]- 1H-pyrazole-4carbonitrile (3)

A mixture of 1-[4-(1,2,3,4-tetrahydronaphthalen-7-yl)thiazol-2-yl]hydrazine (2.45 g, $0.01 \mathrm{~mol})$ and ethoxymethylenemalononitrile (1.22 g, $0.01 \mathrm{~mol})$ in $30 \mathrm{ml}$ absolute ethanol was refluxed for $3 \mathrm{hr}$. Then poured onto ice/cold water, the formed precipitate was filtered, washed several times with water, dried and recrystallized from ethanol to give the title compound 3.

Yield 70\%, mp. 141-143 ${ }^{\circ} \mathrm{C}$; IR (KBr, $\left.\mathrm{cm}^{-1}\right)$ : 3233, $3142\left(\mathrm{NH}_{2}\right)$, 2929, $2853\left(\mathrm{CH}_{2}\right.$ tetralin protons) and $2210(\mathrm{CN}) ;{ }^{1} \mathrm{H}$ NMR $\left(\mathrm{CHCl}_{3}\right)$ : $\delta 1.57-1.82\left(\mathrm{~m}, 4 \mathrm{H}, 2\left(\mathrm{CH}_{2}\right)\right.$ tetralin), 2.56-2.80 (m, $4 \mathrm{H}, 2\left(\mathrm{CH}_{2}\right)$ tetralin), 4.60 (s, $2 \mathrm{H}, \mathrm{NH}_{2}, \mathrm{D}_{2} \mathrm{O}$ exchangeable), 6.70-8.57 (m, $5 \mathrm{H}$, CH-tetralin, thiazole, pyrazole protons); $\mathrm{MS}$, m/z (\%): $322\left[\mathrm{M}^{+1}\right]$ (100); Anal. For $\mathrm{C}_{17} \mathrm{H}_{15} \mathrm{~N}_{5} \mathrm{~S}$ (321.40): Calcd. C, 63.53; $\mathrm{H}$, 4.70; N, 21.79; Found: C, 63.21; H, 4.33; N, 21.50.

5-(Ethoxymetheleneamino)-1-[4-(1,2,3,4- tetrahydronaphthalen-7-yl) thiazol-2-yl]1 H-pyrazole-4-carbonitrile (4)

A mixture of compound $3(0.65 \mathrm{~g}, 0.002 \mathrm{~mol})$ and triethyorthoformate $(1.0 \mathrm{ml})$ in $20 \mathrm{ml}$ acetic acid was refluxed for $5 \mathrm{hr}$. Then poured onto ice/cold water, the formed precipitate was filtered, washed several times with water, dried and recrystallized from ethanol to give the title compound 4 .

Yield 64\%, mp. 188-190 ${ }^{\circ} \mathrm{C}$; IR (KBr, cm $\left.{ }^{-1}\right)$ : 2925, $2856\left(\mathrm{CH}_{2}\right.$ tetralin), 2218 $(\mathrm{CN}), 1684(\mathrm{~N}=\mathrm{CH}) . ;{ }^{1} \mathrm{H}$ NMR $\left(\mathrm{CHCl}_{3}\right): \delta 1.24\left(\mathrm{t}, 3 \mathrm{H},-\mathrm{CH}_{2} \mathrm{CH}_{3}\right), 1.60-1.79(\mathrm{~m}$, $4 \mathrm{H}, 2\left(\mathrm{CH}_{2}\right)$ tetralin), 2.56-2.79 (m, 4H, $2\left(\mathrm{CH}_{2}\right)$ tetralin),3.44 (q, $\left.2 \mathrm{H},-\mathrm{CH}_{2} \mathrm{CH}_{3}\right)$, 7.06-7.91 (m, 6H, CH-tetralin, thiazole, pyrazole protons, $\mathrm{N}=\mathrm{CH}$ ); $\mathrm{MS}, \mathrm{m} / \mathrm{z}(\%)$ : 373 [M-4] (3) and $43\left[\mathrm{C}_{3} \mathrm{H}_{7}\right]$ (100); Anal. For $\mathrm{C}_{20} \mathrm{H}_{19} \mathrm{~N}_{5} \mathrm{OS}$ (377.46): Calcd. C, 63.64; H, 5.07; N, 18.55; Found: C, 63.44; H, 5.21; N, 18.31.

Ethyl 4-cyano-1-[4-(1,2,3,4-tetrahydronaphthalen-7-yl)thiazol-2-yl]-1H-pyrazol5-ylcarbamate (5)

A mixture of compound 3 ( $0.65 \mathrm{~g}, 0.002 \mathrm{~mol})$, ethyl chloroformate $(0.22 \mathrm{ml}$, $0.01 \mathrm{~mol}$ ) and anhydrous sodium carbonate $(1 \mathrm{~g})$ in $20 \mathrm{ml}$ tetrahydrofuran was refluxed for $5 \mathrm{hr}$. Then poured onto ice/cold water, the formed precipitate was filtered, washed several times with water, dried and recrystallized from ethanol to give the title compound 5 .

Yield 68\%, mp. 200-202 ${ }^{\circ} \mathrm{C}$; IR (KBr, $\left.\mathrm{cm}^{-1}\right)$ : $3221(\mathrm{NH}), 2927,2849\left(\mathrm{CH}_{2}\right.$ tetralin protons), $2215(\mathrm{CN})$ and 1692 (CO amide); ${ }^{1} \mathrm{H}$ NMR $\left(\mathrm{CHCl}_{3}\right)$ : $\delta 1.45$ (t, 3H, $\left.\mathrm{CO}_{2} \mathrm{CH}_{2} \mathrm{CH}_{3}\right)$, 1.70-1.79 (m, 4H, $2\left(\mathrm{CH}_{2}\right)$ tetralin), 2.72-2.79 (m, 4H, $2\left(\mathrm{CH}_{2}\right)$ tetralin), 4.34 (q, $2 \mathrm{H},-\mathrm{CO}_{2} \mathrm{CH}_{2} \mathrm{CH}_{3}$ ), 7.06-7.91 (m, 5H, CH-tetralin, thiazole, pyrazole protons), 8.70 (s, $1 \mathrm{H}, \mathrm{NH}, \mathrm{D}_{2} \mathrm{O}$ exchangeable); $\mathrm{MS}, \mathrm{m} / \mathrm{z}(\%): 390$ [M-3] 
(10), $63\left[\mathrm{C}_{5} \mathrm{H}_{3}\right]$ (100); Anal. For $\mathrm{C}_{20} \mathrm{H}_{19} \mathrm{~N}_{5} \mathrm{O}_{2} \mathrm{~S}$ (393.46): Calcd. C, 61.05; H, 4.87; N, 17.80; Found: C, 61.31; H, 4.61; N, 17.92 .

5-Amino-1-[4-(1,2,3,4- tetrahydronaphthalen-7-yl) thiazol-2-yl]- N'-hydroxy-1Hpyrazole-4-carboxamidine (6)

A mixture of compound 3 (0.65 g, $0.002 \mathrm{~mol})$ and hydroxyamine hydrochloride $(0.14 \mathrm{~g}, 0.01 \mathrm{~mol})$ in $20 \mathrm{ml}$ absolute ethanol containing few drops of triethylamine was refluxed for $5 \mathrm{hr}$. Then poured onto ice/cold water, the formed precipitate was filtered, washed several times with water, dried and recrystallized from ethanol to give the title compound 6 .

Yield 75\%, mp.172-174 ${ }^{\circ} \mathrm{C}$; IR (KBr, $\left.\mathrm{cm}^{-1}\right)$ : 3310, 3221, $3154\left(2\left(\mathrm{NH}_{2}\right), \mathrm{OH}\right)$ and 2929, 2851 ( $\mathrm{CH}_{2}$ tetralin protons); MS, m/z (\%): 354 [M-2] (3), 63 [ $\left.\mathrm{C}_{5} \mathrm{H}_{3}\right]$ (100); Anal. For $\mathrm{C}_{17} \mathrm{H}_{18} \mathrm{~N}_{6} \mathrm{OS}$ (354.43): Calcd. C, 57.61; H, 5.12; N, 23.17; Found: C, 57.24; H, 5.34; N, 23.30.

1-[4-(1,2,3,4- Tetrahydronaphthalen-7-yl) thiazol-2-yl]- 1H-4-imino-5-hydroxypyrazolo[3,4-d]pyrimidine (7)

A mixture of compound $6(0.71 \mathrm{~g}, 0.002 \mathrm{~mol})$ and triethyorthoformate $(1.0 \mathrm{ml})$ in $20 \mathrm{ml}$ acetic acid was refluxed for $5 \mathrm{hr}$ then poured onto ice/cold water. The formed precipitate was filtered, washed several times with water, dried and recrystallized from ethanol to give the title compound 7.

Yield 55\%, mp. $187-189^{\circ} \mathrm{C}$; IR $\left(\mathrm{KBr}, \mathrm{cm}^{-1}\right)$ : 3387, $3210(\mathrm{OH}, \mathrm{NH})$ and 2925, $2858\left(\mathrm{CH}_{2}\right.$ tetralin protons); ${ }^{1} \mathrm{H}$ NMR $\left(\mathrm{DMSO}_{6}\right): \delta$ 1.73-1.80 (m, 4H, $2\left(\mathrm{CH}_{2}\right)$ tetralin), 2.74-2.81 (m, 4H, $2\left(\mathrm{CH}_{2}\right)$ tetralin), 7.01-8.01 (m, 6H, CH-tetralin, thiazole, pyrazole, pyrimidine protons); MS, m/z (\%): 365 [M+1] (3), 318 [M$\left(\mathrm{N}_{2} \mathrm{H}_{2} \mathrm{O}\right)$ ] (100); Anal. For $\mathrm{C}_{18} \mathrm{H}_{16} \mathrm{~N}_{6} \mathrm{OS}$ (364.42): Calcd. C, 59.32; H, 4.43; N, 23.06; Found: C, 59.51; H, 4.22; N, 23.25.

1-[4-(1,2,3,4-Tetrahydronaphthalen-7-yl)thiazol-2-yl]-1H-pyrazolo[3,4-d]pyrimidin4(5H)-one (8)

A mixture of compound $3(0.65 \mathrm{~g}, 0.002 \mathrm{~mol})$ and $10 \mathrm{ml}$ formic acid was refluxed for $3 \mathrm{hr}$ then poured onto ice/cold water. The formed precipitate was filtered, washed several times with water, dried and recrystallized from ethanol to give the title compound 8 .

Yield 78\%, mp. $167-169^{\circ} \mathrm{C}$; IR $\left(\mathrm{KBr}, \mathrm{cm}^{-1}\right): 3212(\mathrm{NH}), 2923,2850\left(\mathrm{CH}_{2}\right.$ tetralin) and 1702 (CO); MS, m/z (\%): 348 [M-1] (2) and $45\left[\mathrm{C}_{3} \mathrm{H}_{9}\right]$ (100); Anal. For $\mathrm{C}_{18} \mathrm{H}_{15} \mathrm{~N}_{5} \mathrm{OS}$ (349.41): Calcd. C, 61.87; H, 4.33; N, 20.04; Found: C, 61.71; H, 4.68; N, 20.21.

1-[4-(1,2,3,4-Tetrahydronaphthalen-7-yl) thiazol-2-yl]- 6-methyl-1H-pyrazolo[3,4-d] pyrimidin-4(5H)-one (9)

A mixture of compound 3 (0.65 g, $0.002 \mathrm{~mol})$, acidic anhydride (5 ml) and acetic acid $(5 \mathrm{ml})$ was refluxed for $5 \mathrm{hr}$. The reaction mixture was evaporated

Egypt. J. Chem. 55, No.4 (2012) 
until its half volume then cold. The formed precipitate was filtered, washed several times with water, dried and recrystallized from ethanol to give the title compound 9 .

Yield 70\%, mp. 149-151 ${ }^{\circ} \mathrm{C}$; IR $\left(\mathrm{KBr}, \mathrm{cm}^{-1}\right): 3192(\mathrm{NH}), 2925,2855\left(\mathrm{CH}_{2}\right.$ tetralin) and 1705 (CO); ${ }^{1} \mathrm{H}$ NMR (DMSO- $\left.\mathrm{d}_{6}\right): \delta 1.70-1.85\left(\mathrm{~m}, 4 \mathrm{H}, 2\left(\mathrm{CH}_{2}\right)\right.$ tetralin), $1.88\left(\mathrm{~s}, 3 \mathrm{H}, \mathrm{CH}_{3}\right), 2.56-2.70\left(\mathrm{~m}, 4 \mathrm{H}, 2\left(\mathrm{CH}_{2}\right)\right.$ tetralin), 7.06-8.00 (m, $5 \mathrm{H}, \mathrm{CH}$-tetralin, thiazole, pyrazole protons); MS, m/z (\%): 364 [M+1] (2) and 77 [C $\mathrm{C}_{6} \mathrm{H}_{5}$ ] (100); Anal. For $\mathrm{C}_{19} \mathrm{H}_{17} \mathrm{~N}_{5} \mathrm{OS}$ (363.44): Calcd. C, 62.79; H, 4.71; N, 19.27; Found: C, 62.59; H, 4.52; N, 19.38.

1-[4-(1,2,3,4-Tetrahydronaphthalen-7-yl)thiazol-2-yl]-1H-pyrazolo[3,4-d]pyrimidin4-amine (10)

A mixture of compound $3(0.65 \mathrm{~g}, 0.002 \mathrm{~mol})$ and formamide $(10 \mathrm{ml})$ was refluxed for $1 \mathrm{hr}$. Cool, then, the formed precipitate was filtered, dried and recrystallized from ethanol to give the title compound 10 .

Yield 65\%, mp. 193-195 ${ }^{\circ}$; IR (KBr, cm $\left.{ }^{-1}\right)$ : 3321, $3164\left(\mathrm{NH}_{2}\right)$, 2930, $2850\left(\mathrm{CH}_{2}\right.$ tetralin); MS, m/z (\%): 348 [M+ $\mathrm{M}^{+}$(100); Anal. For $\mathrm{C}_{18} \mathrm{H}_{16} \mathrm{~N}_{6} \mathrm{~S}$ (348.42): Calcd. C, 62.05; H, 4.63; N, 24.12; Found: C, 62.28; H, 4.71; N, 24.29.

1-[4-(1,2,3,4-Tetrahydronaphthalen-7-yl) thiazol-2-yl]-6-methyl-1H-pyrazolo[3,4-d] pyrimidin-4-amine (11)

A mixture of compound $3(0.65 \mathrm{~g}, 0.002 \mathrm{~mol})$ and acetamide $(0.12 \mathrm{~g}, 0.002$ $\mathrm{mol}$ ) in $10 \mathrm{ml}$ dimethylforamide was refluxed for $5 \mathrm{hr}$, then poured onto ice/cold water. The formed precipitate was filtered, washed several times with water, dried and recrystallized from ethanol to give the title compound 11.

Yield 68\%, mp. 201-203 ${ }^{\circ}$; IR ( $\left.\mathrm{KBr}, \mathrm{cm}^{-1}\right)$ : 3289, $3148\left(\mathrm{NH}_{2}\right)$, 2925, $2849\left(\mathrm{CH}_{2}\right.$ tetralin); ${ }^{1} \mathrm{H}$ NMR (DMSO-d 6 ): $\delta 1.77-1.82\left(\mathrm{~m}, 4 \mathrm{H}, 2\left(\mathrm{CH}_{2}\right)\right.$ tetralin), 2.53 (s, 3H, $\left.\mathrm{CH}_{3}\right)$, 2.74-2.80 (m, 4H, $2\left(\mathrm{CH}_{2}\right)$ tetralin), 7.06-8.00 (m, 5H, CH-tetralin, thiazole, pyrazole protons); MS, m/z (\%): 362 [M $\left.\mathrm{M}^{+}\right]$(100); Anal. For $\mathrm{C}_{19} \mathrm{H}_{18} \mathrm{~N}_{6} \mathrm{~S}$ (362.45): Calcd. C, 62.96; H, 5.01; N, 23.19; Found: C, 62.64; H, 5.22; N, 23.41.

1-[4-(1,2,3,4-Tetrahydronaphthalen-7-yl)thiazol-2-yl]-1H-pyrazolo[3,4-d] pyrimidine 4,6(5H,7H)-dithione (12)

A mixture of compound 3 ( $0.65 \mathrm{~g}, 0.002 \mathrm{~mol})$, potassium hydroxide $(0.5 \mathrm{~g} / 1 \mathrm{ml}$ water) and dimethylsulfoxide $(5 \mathrm{ml})$ was cooled at $0-5^{\circ} \mathrm{C}$. Then, carbon disulphide $(1 \mathrm{ml})$ was added dropwise and the reaction mixture was stirred at room temperature for $2 \mathrm{hr}$. The reaction mixture was concentrated and poured onto ice/cold water. The formed precipitate was filtered, washed several times with water, dried and recrystallized from ethanol to give the title compound 12.

Yield 60\%, mp. 177-179 ${ }^{\circ}$; IR (KBr, cm $\left.{ }^{-1}\right): 3189,3153(2 \mathrm{NH}), 2920,2855\left(\mathrm{CH}_{2}\right.$ tetralin) and 1151, 1180 (2C=S); MS, m/z (\%): 395 [M-2] (16) and 364 [M-SH] 
(100); Anal. For $\mathrm{C}_{18} \mathrm{H}_{15} \mathrm{~N}_{5} \mathrm{~S}_{3}$ (397.54): Calcd. C, 54.38; H, 3.80; N, 17.62; Found: C, 54.46; H, 3.64; N, 17.88 .

5-Substituted- 4,5- dihydro-1-[4-(1,2,3,4-tetrahydronaphthalen-7-yl) thiazol-2yl]-4-imino-1H-pyrazolo[3,4-d]pyrimidine-6(7H)-thione (13a-d)

A mixture of compound $3(0.65 \mathrm{~g}, 0.002 \mathrm{~mol})$ and isothiocynate derivatives namely; ethylisothiocynate, cyclohexylisothiocynate, phenylisothiocynate and/or o-tolylisothiocynate $(0.002 \mathrm{~mol})$ in dioxane $(20 \mathrm{ml})$ and pyridine $(1 \mathrm{ml})$ was refluxed for $5 \mathrm{hr}$. The formed precipitate was filtered, washed several times with water, dried and recrystallized from ethanol to give the title compound 13a-d.

5-Ethyl-4,5-dihydro-1-[4-(1,2,3,4-tetrahydronaphthalen-7-yl)thiazol-2-yl]-4imino-1H-pyrazolo[3,4-d]pyrimidine-6(7H)-thione (13a)

Yield 68\%, mp. 163-165 ${ }^{\circ} \mathrm{C}$; IR (KBr, cm $\left.{ }^{-1}\right)$ : 3177, 3153 (2NH), 2925, 2848 $\left(\mathrm{CH}_{2}\right.$ tetralin) and $1150(\mathrm{C}=\mathrm{S}) ;{ }^{1} \mathrm{H}$ NMR $\left(\mathrm{DMSO}-\mathrm{d}_{6}\right): \delta 1.34\left(\mathrm{t}, 3 \mathrm{H},-\mathrm{CH}_{2} \mathrm{CH}_{3}\right)$, 1.72-1.78 (m, 4H, $2\left(\mathrm{CH}_{2}\right)$ tetralin), 2.72-2.80 (m, 4H, $2\left(\mathrm{CH}_{2}\right)$ tetralin), $3.56(\mathrm{q}$, $2 \mathrm{H},-\mathrm{CH}_{2} \mathrm{CH}_{3}$ ), 4.21 (s, $1 \mathrm{H}, \mathrm{NH}, \mathrm{D}_{2} \mathrm{O}$ exchangeable), 7.02-7.98 (m, 5H, CHtetralin, thiazole, pyrazole protons), 8.87 (s, 1H, NH, $\mathrm{D}_{2} \mathrm{O}$ exchangeable); MS, m/z (\%): 409 [M $\mathrm{M}^{+}$(21), 65 [ $\left.\mathrm{C}_{5} \mathrm{H}_{5}\right]$ (100) ; Anal. For $\mathrm{C}_{20} \mathrm{H}_{20} \mathrm{~N}_{6} \mathrm{~S}_{2}$ (408.54): Calcd. C, 58.80; H, 4.93; N, 20.57; Found: C, 58.66; H, 5.04; N, 20.34.

5-Cyclohexyl-4,5-dihydro-1- [4-(1,2,3,4-tetrahydronaphthalen-7-yl)thiazol-2yl]-4-imino-1H-pyrazolo[3,4-d]pyrimidine-6(7H)-thione $(13 b)$

Yield 62\%, mp. 172-174 ${ }^{\circ} \mathrm{C}$; IR (KBr, $\left.\mathrm{cm}^{-1}\right)$ : 3186, 3161 (2NH), 2924, 2850 $\left(\mathrm{CH}_{2}\right.$ tetralin) and $1159(\mathrm{C}=\mathrm{S}) ;{ }^{1} \mathrm{H}$ NMR $\left(\mathrm{DMSO}-\mathrm{d}_{6}\right): \delta 1.41-1.861(\mathrm{~m}, 14 \mathrm{H}, 7$ $\left(\mathrm{CH}_{2}\right)$ tetralin, cyclohexyl ring), 2.63-2.67 (m, 1H, N-cyclohexyl), 2.76-2.81 (m, $4 \mathrm{H}, 2\left(\mathrm{CH}_{2}\right)$ tetralin), $4.34\left(\mathrm{~s}, 1 \mathrm{H}, \mathrm{NH}, \mathrm{D}_{2} \mathrm{O}\right.$ exchangeable), 7.03-7.89 (m, 5H, $\mathrm{CH}$-tetralin, thiazole, pyrazole protons), 9.02 (s, $1 \mathrm{H}, \mathrm{NH}, \mathrm{D}_{2} \mathrm{O}$ exchangeable); MS, m/z (\%): $462\left[\mathrm{M}^{+}\right]$(9), $77\left[\mathrm{C}_{6} \mathrm{H}_{5}\right]$ (100); Anal. For $\mathrm{C}_{24} \mathrm{H}_{26} \mathrm{~N}_{6} \mathrm{~S}_{2}$ (462.63): Calcd. C, 62.31; H, 5.66; N, 18.17; Found: C, 62.54; H, 5.28; N, 18.36.

4,5-Dihydro-1-[4- (1,2,3,4-tetrahydronaphthalen-7-yl) thiazol-2-yl]- 4-imino-5phenyl-1H-pyrazolo[3,4-d]pyrimidine-6(7H)-thione $(13 c)$

Yield 65\%, mp. 181-183 ${ }^{\circ} \mathrm{C}$; IR (KBr, $\left.\mathrm{cm}^{-1}\right)$ : 3171, 3150 (2NH), 2925, 2845 $\left(\mathrm{CH}_{2}\right.$ tetralin) and $1160(\mathrm{C}=\mathrm{S}) ; \mathrm{MS}, \mathrm{m} / \mathrm{z}(\%): 455$ [M-1] (11), $64\left[\mathrm{C}_{5} \mathrm{H}_{4}\right](100)$; Anal. For $\mathrm{C}_{24} \mathrm{H}_{20} \mathrm{~N}_{6} \mathrm{~S}_{2}$ (456.59): Calcd. C, 63.13; H, 4.42; N, 18.41; Found: C, 63.28; H, 4.22; N, 18.75 .

4,5-Dihydro-1-[4-(1,2,3,4-tetrahydronaphthalen- 7-yl)thiazol-2-yl]- 4-imino5-p-tolyl-1H-pyrazolo[3,4-d]pyrimidine-6(7H)-thione (13d)

Yield 71\%, mp. 191-193 ${ }^{\circ} \mathrm{C}$; IR (KBr, $\left.\mathrm{cm}^{-1}\right): 3180,3144$ (2NH), 2926, 2851 $\left.\left(\mathrm{CH}_{2} \text { tetralin) and } 1152(\mathrm{C}=\mathrm{S}) ;{ }^{1} \mathrm{H} \text { NMR (DMSO-d }\right)_{6}\right): \delta$ 1.68-1.82 (m, 4H, 2 $\left(\mathrm{CH}_{2}\right)$ tetralin), $2.20\left(\mathrm{~s}, 3 \mathrm{H}, \mathrm{CH}_{3}\right), 2.70-2.73\left(\mathrm{~m}, 4 \mathrm{H}, 2\left(\mathrm{CH}_{2}\right)\right.$ tetralin), $4.14(\mathrm{~s}$, $1 \mathrm{H}, \mathrm{NH}, \mathrm{D}_{2} \mathrm{O}$ exchangeable), 7.02-8.40 (m, 9H, CH-tetralin, thiazole, pyrazole protons, Ar-H), 9.21 (s, 1H, NH, $\mathrm{D}_{2} \mathrm{O}$ exchangeable); MS, m/z (\%): $472[\mathrm{M}+1]$ (4), $76\left[\mathrm{C}_{6} \mathrm{H}_{4}\right]$ (100); Anal. For $\mathrm{C}_{25} \mathrm{H}_{22} \mathrm{~N}_{6} \mathrm{~S}_{2}$ (470.61): Calcd. C, 63.80; H, 4.71; N, 17.86; Found: C, 63.66; H, 4.85; N, 17.59 .

Egypt. J. Chem. 55, No.4 (2012) 
4-Amino-6,7-dihydro-1- [4-(1,2,3,4- tetrahydronaphthalen-7-yl) thiazol-2-yl]-6imino-1H-pyrazolo[3,4-b]pyridine-5-carbonitrile (14)

A mixture of compound $3(0.65 \mathrm{~g}, 0.002 \mathrm{~mol})$ and malononitrile $(0.14 \mathrm{~g}$, $0.002 \mathrm{~mol}$ ) in $20 \mathrm{ml}$ absolute ethanol containing few drops of piperdine was refluxed for $5 \mathrm{hr}$, then poured onto ice/cold water. The formed precipitate was filtered, washed several times with water, dried and recrystallized from ethanol to give the title compound 14 .

Yield 65\%, mp. >300 ${ }^{\circ} \mathrm{C}$; IR (KBr, $\left.\mathrm{cm}^{-1}\right)$ : 3343, 3198, 3149 (2NH, $\left.\mathrm{NH}_{2}\right), 2921$, $2851\left(\mathrm{CH}_{2}\right.$ tetralin) and $2198(\mathrm{CN}) ;{ }^{1} \mathrm{H}$ NMR $\left(\mathrm{DMSO}-\mathrm{d}_{6}\right): \delta 1.51-1.71(\mathrm{~m}, 4 \mathrm{H}, 2$ $\left(\mathrm{CH}_{2}\right)$ tetralin), 2.69-2.79 (m, 4H, $2\left(\mathrm{CH}_{2}\right)$ tetralin), 7.01-8.10 (m, 5H, CHtetralin, thiazole, pyrazole protons); MS, m/z (\%): 361 [M-CN] (5), $56\left[\mathrm{C}_{4} \mathrm{H}_{8}\right]$ (100); Anal. For $\mathrm{C}_{20} \mathrm{H}_{17} \mathrm{~N}_{7} \mathrm{~S}$ (387.46): Calcd. C, 62.00; H, 4.42; N, 25.30; Found: C, 62.13; H, 4.62; N, 25.54.

5-(Substituted amino)-1-(4-(1,2,3,4-tetrahydronaphthalen-7-yl) thiazol-2-yl)-1Hpyrazole-4-carbonitriles (15a-c)

A mixture of compound $3(0.65 \mathrm{~g}, 0.002 \mathrm{~mol})$ and aldehyde derivatives namely; 4-methoxybenzaldehyde, 2-thiophene carboxaldehyde and/or 3indolylcarboxaldehyde $(0.002 \mathrm{~mol})$ in $15 \mathrm{ml}$ acetic acid was refluxed for $5 \mathrm{hr}$. Then, the reaction mixture was poured onto ice/cold water, the formed precipitate was filtered, washed several times with water, dried and recrystallized from ethanol to give the title compound 15a-c.

5-(4-Methoxybenzylideneamino)-1-[4-(1,2,3,4-tetrahydronaphthalen-7-yl)thiazol2-yl]-1H-pyrazole-4-carbonitrile (15a)

Yield 73\%, mp. 2105-217 ${ }^{\circ} \mathrm{C}$; IR $\left(\mathrm{KBr}, \mathrm{cm}^{-1}\right)$ : 2924, $2850\left(\mathrm{CH}_{2}\right.$ tetralin), 2216 $(\mathrm{CN})$ and $1645(\mathrm{~N}=\mathrm{CH}) ;{ }^{1} \mathrm{H}$ NMR (DMSO-d $\left.{ }_{6}\right): \delta 1.71-1.85\left(\mathrm{~m}, 4 \mathrm{H}, 2\left(\mathrm{CH}_{2}\right)\right.$ tetralin), 2.70-.2.80 (m, 4H, $2\left(\mathrm{CH}_{2}\right)$ tetralin), $3.82\left(\mathrm{~s}, 3 \mathrm{H}, \mathrm{OCH}_{3}\right), 7.05-8.10(\mathrm{~m}$, $10 \mathrm{H}$, CH-tetralin, thiazole, pyrazole protons, $\mathrm{Ar}-\mathrm{H}, \mathrm{N}=\mathrm{CH}$ ); $\mathrm{MS}, \mathrm{m} / \mathrm{z}(\%): 440$ $\left[\mathrm{M}^{+1}\right]$ (34), $56\left[\mathrm{C}_{4} \mathrm{H}_{8}\right](100)$; Anal. For $\mathrm{C}_{25} \mathrm{H}_{21} \mathrm{~N}_{5} \mathrm{OS}$ (439.53): Calcd. C, 68.32; $\mathrm{H}$, 4.82; N, 15.93; Found: C, 68.42; H, 4.69; N, 15.77.

5-[(Thiophen- 2-yl) methyleneamino]-1- [4-(1,2,3,4- tetrahydronaphthalen- 7-yl] thiazol-2-yl)-1H-pyrazole-4-carbonitrile (15b)

Yield 68\%, mp. 205-207 ${ }^{\circ}$; IR (KBr, cm $\left.{ }^{-1}\right)$ : 2925, $2853\left(\mathrm{CH}_{2}\right.$ tetralin), 2216 (CN) and $1649(\mathrm{~N}=\mathrm{CH}) ; \mathrm{MS}, \mathrm{m} / \mathrm{z}(\%): 415\left[\mathrm{M}^{+}\right]$(15), $77\left[\mathrm{C}_{6} \mathrm{H}_{5}\right](100)$; Anal. For $\mathrm{C}_{22} \mathrm{H}_{17} \mathrm{~N}_{5} \mathrm{~S}_{2}$ (415.53): Calcd. C, 63.59; H, 4.12; N, 16.85; Found: C, 63.37; H, 4.39; N, 16.92.

5-[(1H-Indol-3-yl)methyleneamino]-1-[4-(1,2,3,4-tetrahydronaphthalen-7-yl) thiazol-2-yl]-1H-pyrazole-4-carbonitrile (15c)

Yield 71\%, mp. 224-226 ${ }^{\circ} \mathrm{C}$; IR (KBr, cm $\left.{ }^{-1}\right): 3111(\mathrm{NH}), 2926,2853\left(\mathrm{CH}_{2}\right.$ tetralin), $2216(\mathrm{CN})$ and $1654(\mathrm{~N}=\mathrm{CH}) ; \mathrm{MS}, \mathrm{m} / \mathrm{z}(\%): 448\left[\mathrm{M}^{+}\right](8), 65\left[\mathrm{C}_{5} \mathrm{H}_{5}\right]$ (100); Anal. For $\mathrm{C}_{26} \mathrm{H}_{20} \mathrm{~N}_{6} \mathrm{~S}$ (448.54): Calcd. C, 69.62; H, 4.49; N, 18.74; Found: C, 69.87; H, 4.66; N, 18.53. 
6-(Chloromethyl)-1-[4-(1,2,3,4-tetrahydronaphthalen-7-yl)thiazol-2-yl]-1H-pyrazolo [3,4-d]pyrimidin-4(5H)-one (16)

A mixture of compound 3 (0.65 g, $0.002 \mathrm{~mol})$ and chloracetylchloride $(0.23 \mathrm{ml}$, $0.002 \mathrm{~mol}$ ) in $20 \mathrm{ml}$ dry benzene was refluxed for $5 \mathrm{hr}$. The formed precipitate was filtered, dried and recrystallized from ethanol to give the title compound 16 .

Yield 71\%, mp. 191-192 ${ }^{\circ} \mathrm{C}$; IR $\left(\mathrm{KBr}, \mathrm{cm}^{-1}\right): 3123(\mathrm{NH}), 2926,2850\left(\mathrm{CH}_{2}\right.$ tetralin) and $1709(\mathrm{CO}) ;{ }^{1} \mathrm{H}$ NMR $\left(\mathrm{DMSO}_{-} \mathrm{d}_{6}\right): \delta$ 1.62-1.81 (m, 4H, $2\left(\mathrm{CH}_{2}\right)$ tetralin), 2.60-2.80 (m, 4H, $2\left(\mathrm{CH}_{2}\right)$ tetralin), 4.19 (s, 3H, $-\mathrm{CH}_{2} \mathrm{Cl}$,), 7.01-8.01 (m, 5H, CH-tetralin, thiazole, pyrazole protons); MS, m/z (\%): 371, 369 [M-CO] (5, 2) and $27\left[\mathrm{C}_{2} \mathrm{H}_{3}\right]$ (100); Anal. For $\mathrm{C}_{19} \mathrm{H}_{16} \mathrm{ClN}_{5} \mathrm{OS}$ (397.88): Calcd. C, 57.35; H, 4.05; N, 17.60; Found: C, 57.55; H, 4.35; N, 17.92.

5-Amino-1-[4-(1,2,3,4- tetrahydronaphthalen-7-yl) thiazol-2-yl]-1H-pyrazole-4carboxamide (17)

Compound 3 (0.65 g, $0.002 \mathrm{~mol})$ was added portionwise to $10 \mathrm{ml}$ conc. sulfuric acid at $0-5^{\circ} \mathrm{C}$. Then , the reaction mixture was stirred for $15 \mathrm{~min}$ at room temperature and poured onto ice/cold water. The formed precipitate was filtered, washed several times with water, dried and recrystallized from ethanol to give the title compound 17.

Yield 73\%, mp. $281-283^{\circ} \mathrm{C}$; IR $\left(\mathrm{KBr}, \mathrm{cm}^{-1}\right)$ : 3226, 3181, $3123\left(2 \mathrm{NH}_{2}\right), 2925$, $2855\left(\mathrm{CH}_{2}\right.$ tetralin) and $1671(\mathrm{CO}) ; \mathrm{MS}, \mathrm{m} / \mathrm{z}(\%): 339\left[\mathrm{M}^{+}\right](21 \%)$ and $76\left[\mathrm{C}_{6} \mathrm{H}_{4}\right]$ (100); Anal. For $\mathrm{C}_{17} \mathrm{H}_{17} \mathrm{~N}_{5} \mathrm{OS}$ (339.41): Calcd. C, 60.16; H, 5.05; N, 20.63; Found: C, 60.40; H, 5.28; N, 20.51.

1-[4-(1,2,3,4-Tetrahydronaphthalen-7-yl)thiazol-2-yl]-1H-pyrazol-5-amine (18)

A mixture of compound $3(0.65 \mathrm{~g}, 0.002 \mathrm{~mol})$ and $20 \mathrm{ml}$ sulfuric acid (50\%) was refluxed for $2 \mathrm{hr}$, cooled, poured onto ice/cold water. The formed precipitate was filtered, dried and recrystallized from ethanol to give the title compound 18 .

Yield 65\%, mp. $>300^{\circ} \mathrm{C}$; IR $\left(\mathrm{KBr}, \mathrm{cm}^{-1}\right)$ : $3217\left(\mathrm{NH}_{2}\right), 2925,2852\left(\mathrm{CH}_{2}\right.$ tetralin); MS, m/z (\%): 296 [ $\left.\mathrm{M}^{+}\right]$(100); Anal. For $\mathrm{C}_{16} \mathrm{H}_{16} \mathrm{~N}_{4} \mathrm{~S}$ (296.39): Calcd. C, 64.84; H, 5.44; N, 18.90; Found: C, 64.70; H, 5.31; N, 19.15.

1-[4-(1,2,3,4-Tetrahydronaphthalen-7-yl)thiazol-2-yl]-4-(1H-imidazol-2-yl)-1Hpyrazol-5-amine (19)

A mixture of compound $3(0.65 \mathrm{~g}, 0.002 \mathrm{~mol})$ and diaminoethane $(5 \mathrm{ml})$ than carbon disulphide $(1 \mathrm{ml})$ was added dropwise with stirring at room temperature. The reaction mixture was heated on water bath for $5 \mathrm{hr}$. The formed precipitate was filtered, dried and recrystallized from ethanol to give the title compound 19 .

Yield 68\%, mp. 154-156 ${ }^{\circ} \mathrm{C}$; IR (KBr, cm $\left.{ }^{-1}\right): 3217,3147\left(\mathrm{NH}_{2}\right), 2924,2852\left(\mathrm{CH}_{2}\right.$ tetralin); MS, m/z (\%): $362\left[\mathrm{M}^{+}\right]$(100); Anal. For $\mathrm{C}_{19} \mathrm{H}_{18} \mathrm{~N}_{6} \mathrm{~S}$ (362.45): Calcd. C, 62.96; H, 5.01; N, 23.19; Found: C, 62.80; H, 5.27; N, 23.25. 


\section{Molecular docking}

\section{Preparation of protein and ligands for docking}

The crystal structure of Thymidylate Synthase complexed with Raltitrexed was downloaded from protein data bank (http://www.pdb. org/pdb/home/ home.do) with pdb code $=1 \mathrm{HVY}$ and the site in which the inhibitor was complexes was identified and the surrounding important residues such as Tyr 258, Asp 218, Leu 221, Gly 222, Asn 226, Phe 225, Phe 80, Glu 87, IIe 108, TRP 109, Ala 312, Asn 112 and Leu 192 were recognised. Both the protein and ligands were saved as pdbqt format. Docking was performed as in the Autodock vina and MOE (Table 1). Binding affinities were calculated and the highly ranked compounds were selected and docking was repeated for these selected compounds to confirm their affinity. The docking results have shown that 8 compounds could be potential anticancer agents due to their promising binding and fitting in Thymidylate Synthase. The best conformations and docking poses are shown below.

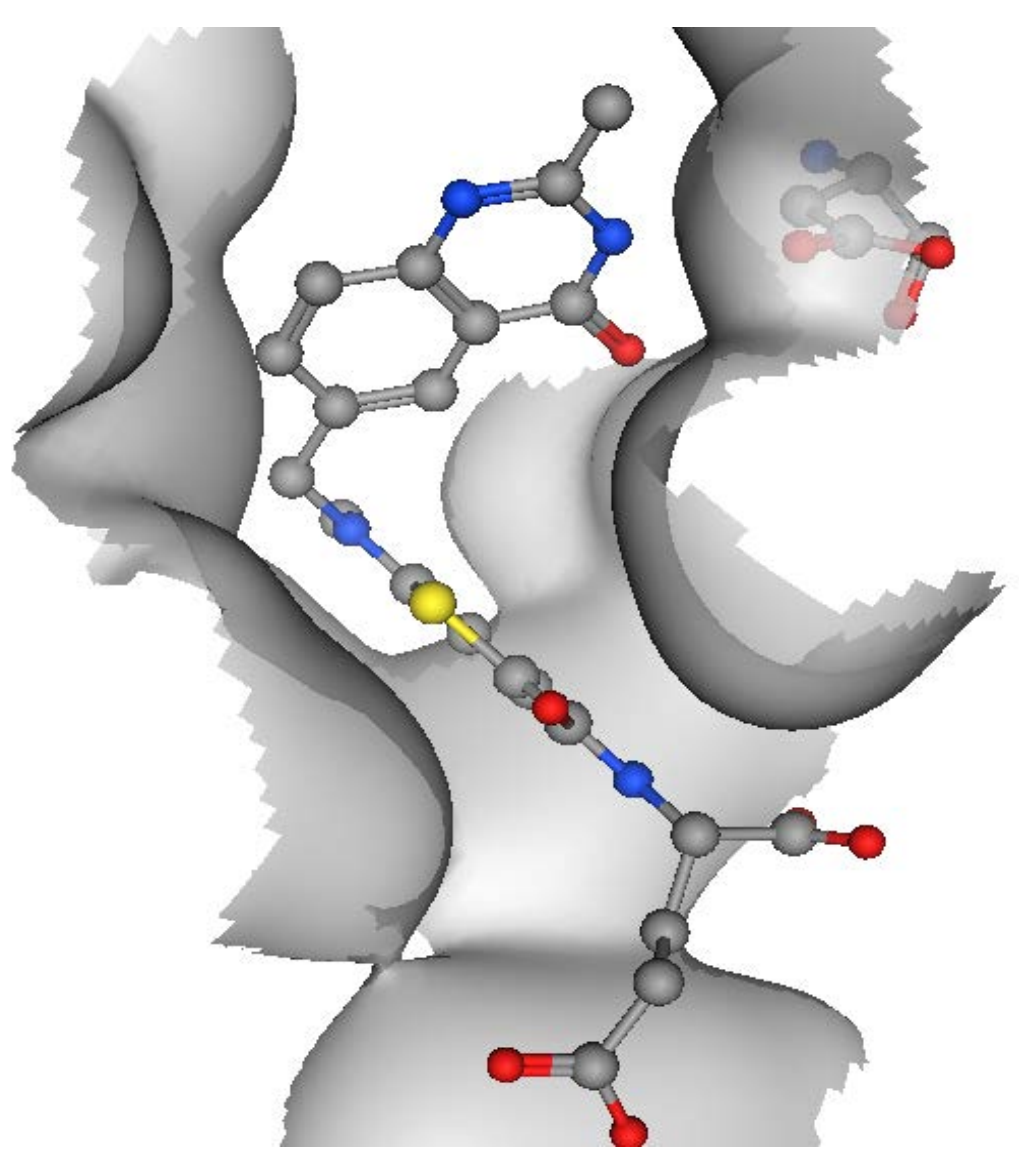

Raltitrexed binding site. Asp 218 is shown close to the binding site.

Egypt. J. Chem. 55, No.4 (2012) 


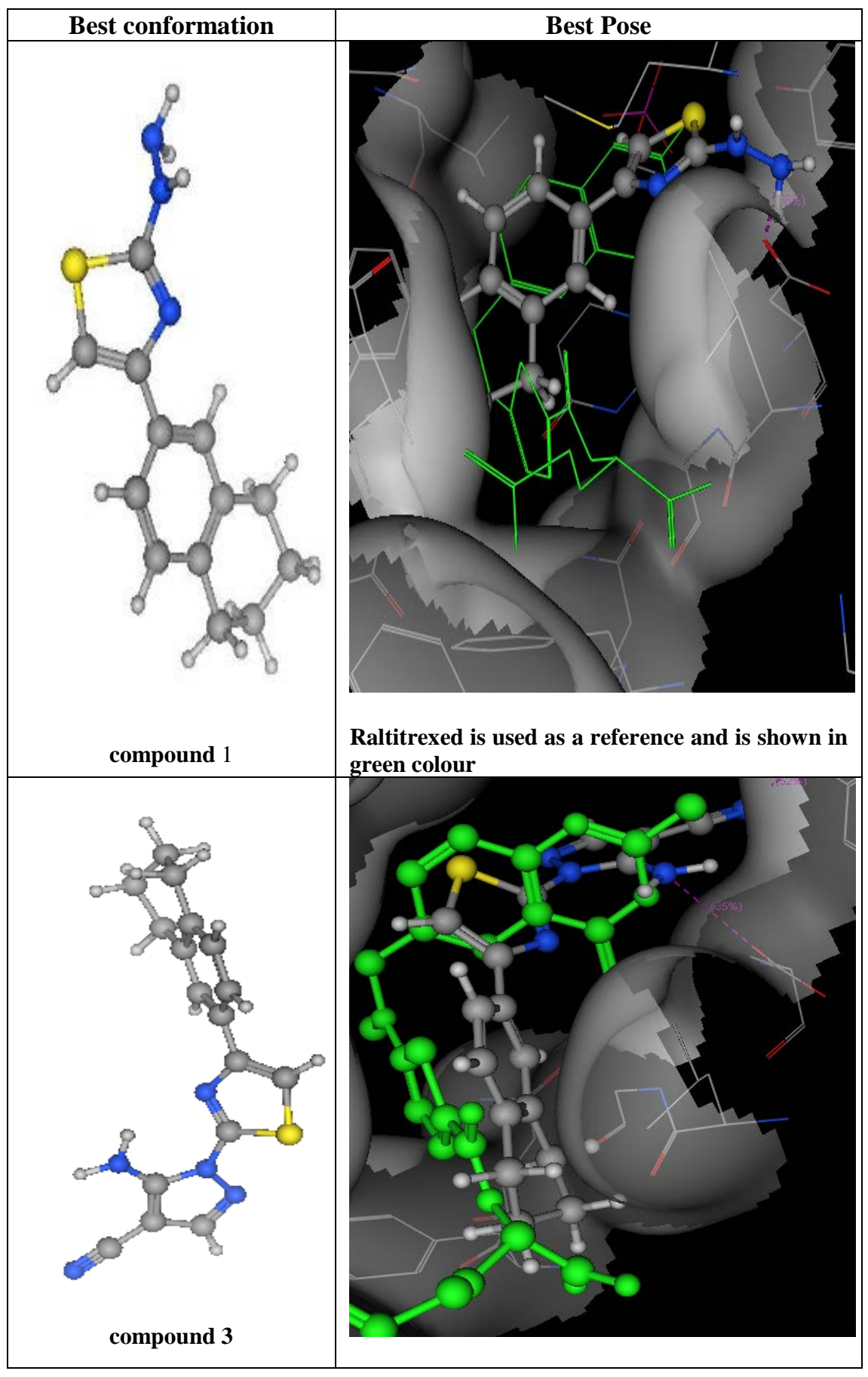

Egypt. J. Chem. 55, No.4 (2012) 


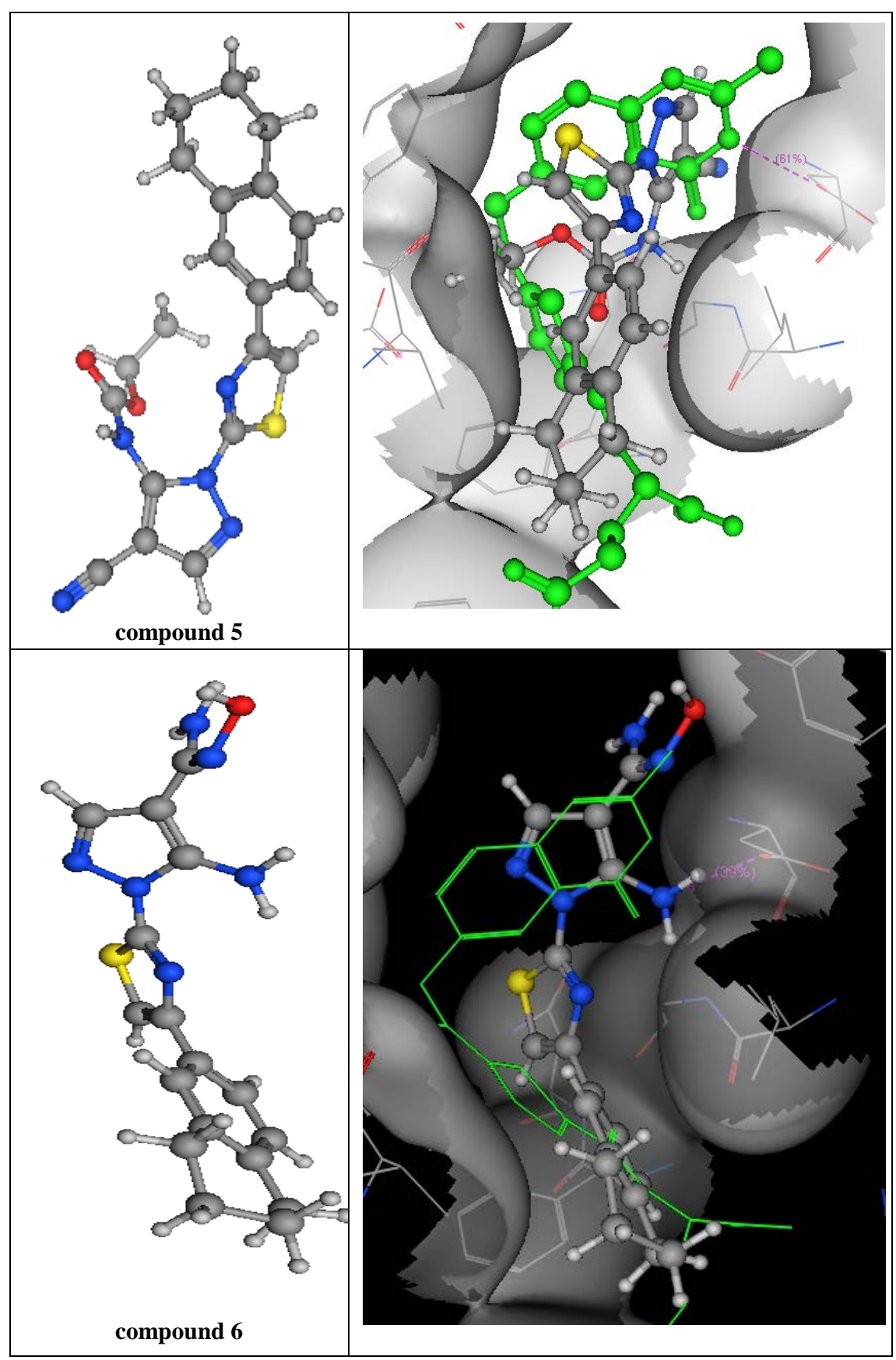

Egypt. J. Chem. 55, No.4 (2012) 


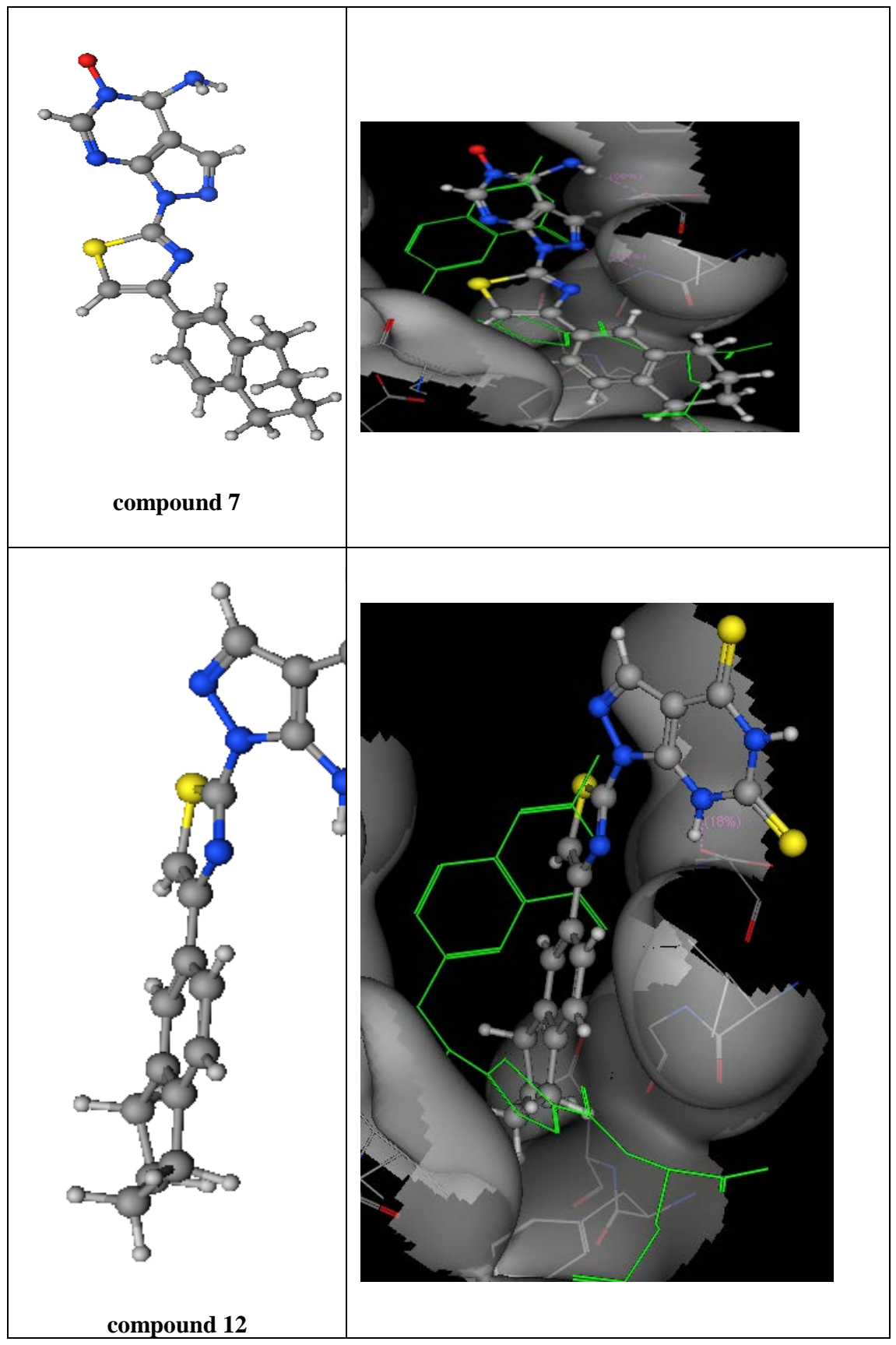

Egypt. J. Chem. 55, No.4 (2012) 
Synthesis, Moleculer Docking and Anticancer Screening of Some Novel...

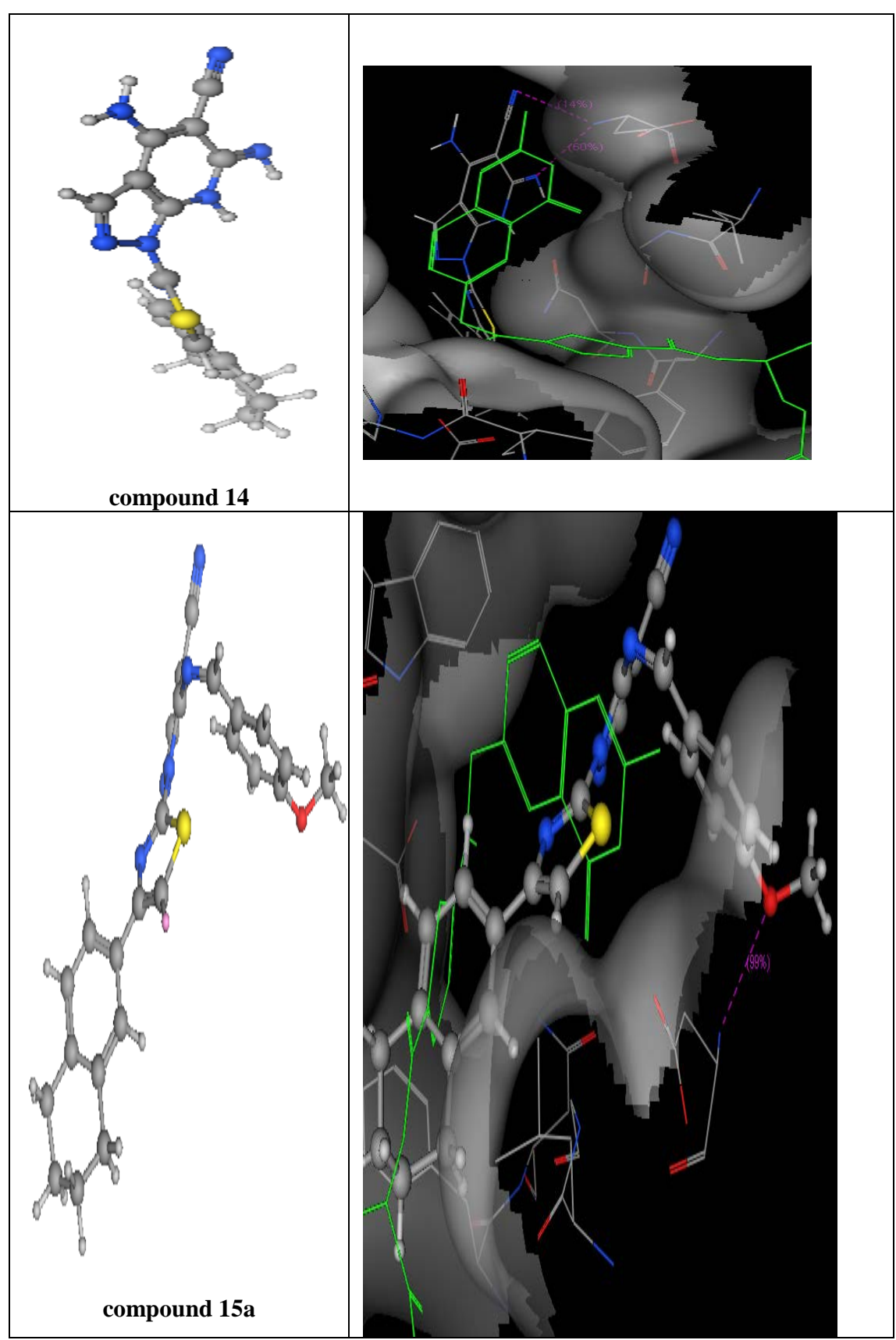

Egypt. J. Chem. 55, No.4 (2012) 
TABLE 1. Docking results of the synthesized compounds .

\begin{tabular}{|c|c|c|c|c|}
\hline Compound & $\begin{array}{c}\text { MOE } \\
\text { Affinity } \\
\text { Kcal/mol }\end{array}$ & $\begin{array}{c}\text { Autodock vina } \\
\text { Affinity } \\
\text { Kcal/mol }\end{array}$ & $\begin{array}{c}\text { Main } \\
\text { Residue }\end{array}$ & Bond strength \\
\hline 1 & --10.80 & -7.5 & Туг 258 & $66 \%$ \\
\hline \multicolumn{5}{|l|}{2} \\
\hline 3 & -9.98 & -6.90 & $\begin{array}{l}\text { Tyr } 258, \\
\text { Asp } 218\end{array}$ & $35 \%$ \\
\hline 4 & -8.5 & -5.98 & No action & No action \\
\hline 5 & -10.98 & -8.70 & Asn 226 & $61.5 \%$ \\
\hline 6 & -10.70 & -7.34 & Asp 218 & $39 \%$ \\
\hline 7 & -12.80 & -7.56 & $\begin{array}{l}\text { Tyr 258, } \\
\text { Asp } 218\end{array}$ & $58 \%$ \\
\hline 8 & -9.88 & -4.5 & Phe 225 & $23 \%$ \\
\hline 9 & -9.1 & -6.3 & Phe 225 & $13 \%$ \\
\hline 10 & -9.5 & -5.8 & Glu 87 & No action \\
\hline 11 & -9.0 & -6.12 & No action & No action \\
\hline 12 & -11.65 & -6.74 & Asp 218 & $39 \%$ \\
\hline 13a & -9.2 & -6.90 & Trp 109 & $34 \%$ \\
\hline $13 b$ & -9.0 & -5.12 & No action & No action \\
\hline $13 c$ & -7.78 & -4.98 & No action & No action \\
\hline 13d & -8.34 & -5.34 & No action & No action \\
\hline 14 & -10.45 & -6.54 & Asp 218 & $60 \%$ \\
\hline $15 a$ & -10.97 & -7.77 & Asp 218 & $68 \%$ \\
\hline $15 b$ & -9.2 & -5.43 & Leu 221 & $26 \%$ \\
\hline $15 c$ & -8.70 & -4.22 & No action & No action \\
\hline 16 & -7.98 & -5.50 & No action & No action \\
\hline 17 & -8.46 & -6.90 & No action & No action \\
\hline 18 & -9.65 & -6.84 & No action & No action \\
\hline
\end{tabular}

According to the docking results, eight compounds showed high affinities to Thymidylate Synthese enzyme. Compounds 1, 3, 5, 6, 7, 12, 14 and 15a have MOE affinities -10.80, -9.98, -10.98, -10.70, -12.80, -11.65, 10.49 and -10.97 $\mathrm{kcal} / \mathrm{mol}$, respectively and Autodock Vina affinities -7.5, -6.90, -8.70, -7.34, 7.56, -6.74, -6.54 and 7.77, respectively.

Most of the tested derivatives showed interaction with Asp218 of the enzyme. It has been found that the hydrazine group of compound 1 was involved in $\mathrm{H}$ bonding with Asp218. While compound 3 exhibited two binding conformations,

Egypt. J. Chem. 55, No.4 (2012) 
one with Tyr258 and the other with Asp218, via the amino and cyano groups. The cyano and amino groups of compounds 5 and 7 participated in H-bonding with Asn 226 and Asp218, respectively. In case of derivative 6, it exhibited two H-bonding interaction with Asp218 and Tyr258 via $\mathrm{NH}_{2}$ and $\mathrm{NOH}$ groups. Finally, compounds 12, 14 and 15a showed conformation that poses H-bonding between Asp218 and NH, CN groups, respectively.

\section{Biological Evaluation}

Material and methods

Cytotoxic effect on human cell line (HePG 2 - MCF 7 - HCT 116)

Cell viability was assessed by the mitochondrial dependent reduction of yellow MTT (3-(4,5-dimethylthiazol-2-yl)-2,5-diphenyl tetrazolium bromide) to purple formazan ${ }^{(27)}$.

All the following procedures were done in a sterile area using a Laminar flow cabinet biosafety class II level (Baker, SG403INT, Sanford, ME, USA). Cells were suspended in RPMI 1640 medium for HePG2- MCF7 and HCT116 DMEM for A549. The media are supplemented with $1 \%$ antibiotic-antimycotic mixture $(10,000 \mathrm{U} / \mathrm{ml}$ Potassium Penicillin, $10,000 \mu \mathrm{g} / \mathrm{ml}$ Streptomycin Sulfate and $25 \mu \mathrm{g} / \mathrm{ml}$ Amphotericin B), 1\% L-glutamine and 10\% fetal bovine serum and kept at $37^{\circ} \mathrm{C}$ under $5 \% \mathrm{CO}_{2}$.

Cells were batch cultured for 10 days, then seeded at concentration of 10x103 cells/well in fresh complete growth medium in 96-well microtiter plastic plates at $37^{\circ} \mathrm{C}$ for $24 \mathrm{hr}$ under $5 \% \mathrm{CO}_{2}$ using a water jacketed carbon dioxide incubator (Sheldon, TC2323, Cornelius, OR, USA). Media was aspirated, fresh medium (without serum) was added and cells were incubated either alone (negative control) or with different concentrations of sample to give a final concentration of (100, 50, 25, 12.5, 6.25, 3.125, 1.56 and $0.78 \mathrm{ug} / \mathrm{ml}$ ). After $48 \mathrm{hr}$ of incubation, medium was aspirated, 40ul MTT salt $(2.5 \mu \mathrm{g} / \mathrm{ml})$ were added to each well and incubated for further four hours at $37^{\circ} \mathrm{C}$ under $5 \% \mathrm{CO}_{2}$. To stop the reaction and dissolving the formed crystals, $200 \mu \mathrm{L}$ of $10 \%$ sodium dodecyl sulphate (SDS) in deionized water was added to each well and incubated overnight at $37^{\circ} \mathrm{C}$. A positive control which composed of $100 \mu \mathrm{g} / \mathrm{ml}$ was used as a known cytotoxic natural agent which gives $100 \%$ lethality under the same conditions ${ }^{(28)}$.

The absorbance was then measured using a microplate multi-well reader (BioRad Laboratories Inc., model 3350, Hercules, California, USA) at $595 \mathrm{~nm}$ and a reference wavelength of $620 \mathrm{~nm}$. A statistical significance was tested between samples and negative control (cells with vehicle) using independent t-test by SPSS 11 program. DMSO is the vehicle used for dissolution of plant extracts and its final concentration on the cells was less than $0.2 \%$. The percentage of change in viability was calculated according to the formula:

((Reading of extract / Reading of negative control) -1) x 100

Egypt. J. Chem. 55, No.4 (2012) 
In vitro cytotoxic screening

Ten of the newly synthesized tetralin derivatives $(3,4,5,6,7,12,14,15 \mathrm{a}, 16$, 19) were selected as representative examples for cytotoxic activity evaluation against colon (HCT116), hepatocellular (HePG2) and breast (MCF7) carcinoma cell line (Table 2 and Fig.1-3).

TABLE 2. $\mathrm{LC}_{50}(\mu \mathrm{g} / \mathrm{ml})$ of the tetralin derivatives on colon cell line (HCT116), human liver carcinoma cell line (HePG2) and human Caucasian breast adenocarcinoma (MCF7) .

\begin{tabular}{|c|c|c|c|}
\hline \multirow[t]{2}{*}{ Comp. No } & HCT116-48 hr & HePG2- 48 hr & MCF7- $48 \mathrm{hr}$ \\
\hline & $\mathrm{LC}_{50}(\mu \mathrm{g} / \mathrm{ml})$ & $\mathrm{LC}_{50}(\mu \mathrm{g} / \mathrm{ml})$ & $\mathrm{LC}_{50}(\mu \mathrm{g} / \mathrm{ml})$ \\
\hline 3 & 46.1 & 50.8 & 44.3 \\
\hline 4 & 55.9 & 30.8 & 30.7 \\
\hline 5 & -------- & -------- & ------- \\
\hline 6 & 52.1 & 45.3 & 50 \\
\hline 7 & -------- & 69.9 & 59.1 \\
\hline 12 & 74.5 & 68.4 & 55.1 \\
\hline 14 & -------- & --------- & -------- \\
\hline $15 a$ & ------- & -------- & 64.5 \\
\hline 16 & -------- & -------- & -------- \\
\hline 19 & 35.5 & 40.7 & 51.9 \\
\hline Doxorubicin & 37.7 & 21.4 & 26.1 \\
\hline DMSO & -------- & -------- & -------- \\
\hline $\begin{array}{l}\text { Negative } \\
\text { control }\end{array}$ & ------- & ------- & ------- \\
\hline
\end{tabular}

$\mathrm{LC}_{50}$ : Lethal concentration of the sample which causes the death of $50 \%$ of cells in $48 \mathrm{hr}$.

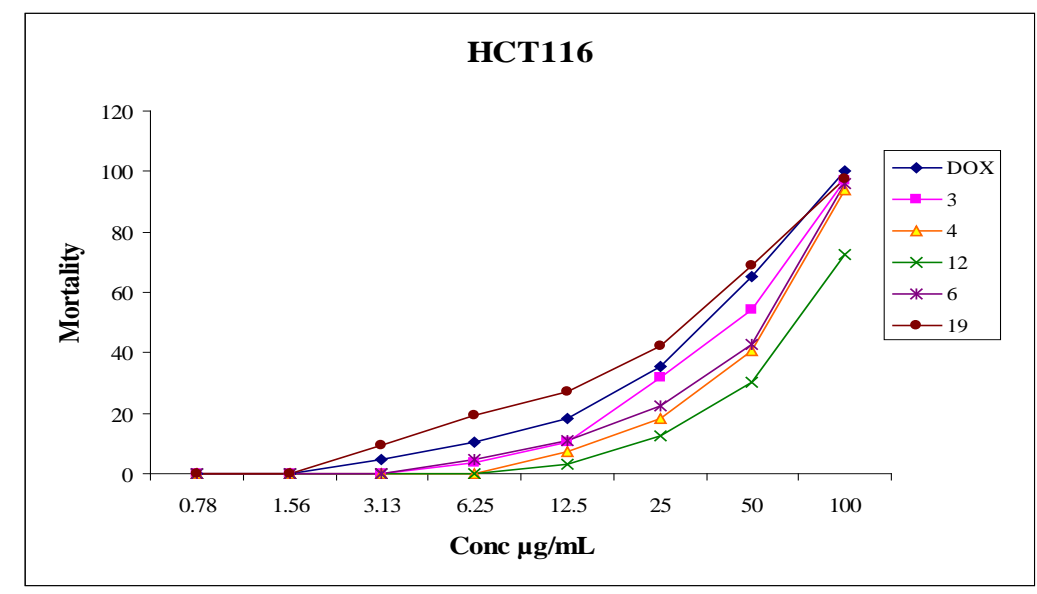

Fig. 1. Cytotoxicity screening of tetralin derivatives against HCT116. 


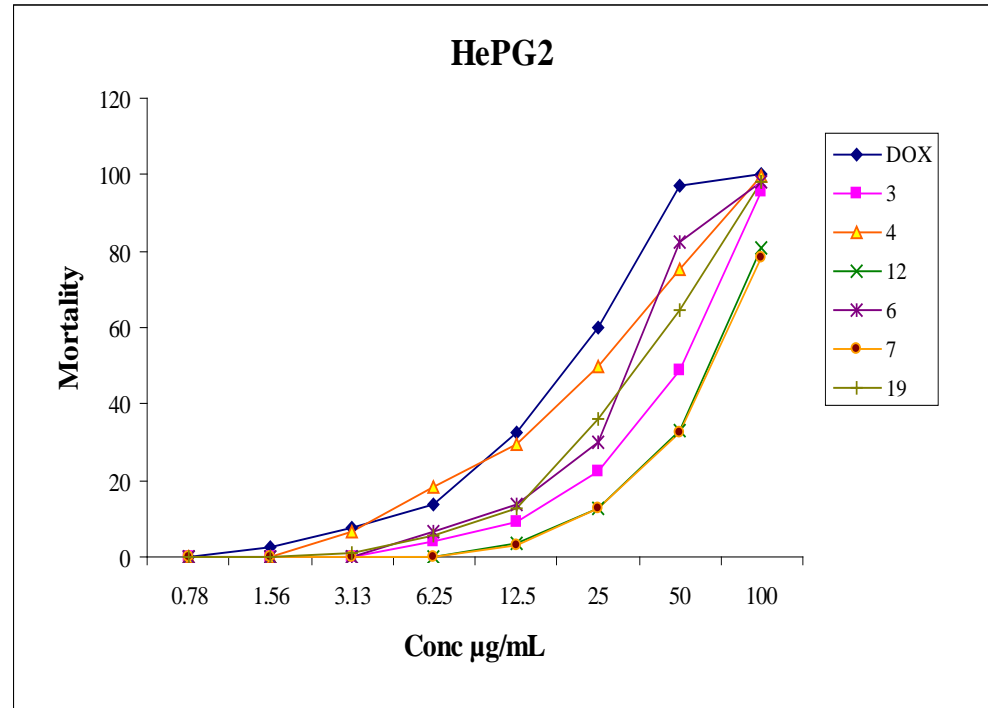

Fig. 2. Cytotoxicity screening of tetralin derivatives against HePG2.

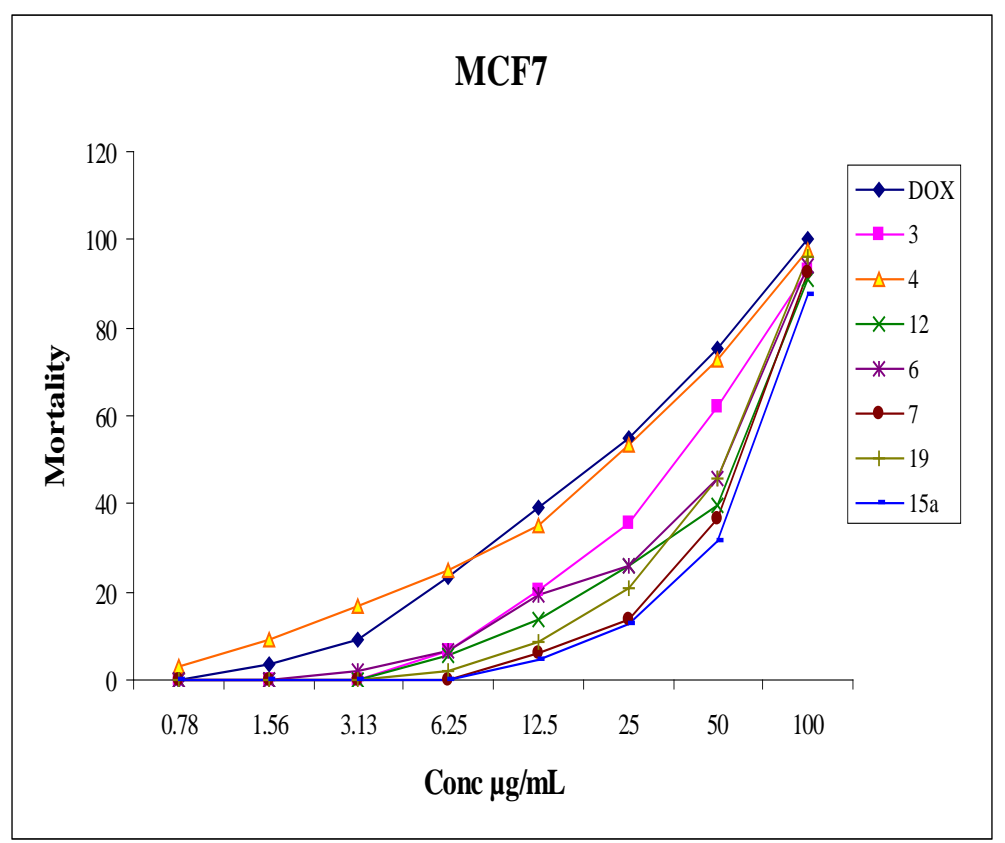

Fig. 3. Cytotoxicity screening of tetralin derivatives against MCF7.

Egypt. J. Chem. 55, No.4 (2012) 
Structure activity relationship

Ten of the newly synthesized derivatives $(3,4,5,6,7,12,14,15 a 16,19)$ were selected as representative examples for cytotoxic activity evaluation against colon (HCT116), hepatocellular (HePG2) and breast (MCF7) carcinoma cell lines.

According to the resultant data of HCT116 cell lines: it has been noticed that the parent compound 3 carrying 4-cyano-5-aminopyrazole moiety attached to thiazolo-tetralin ring showed efficient cytotoxic activity $\left(\mathrm{LC}_{50}: 46.1 \mu \mathrm{g} / \mathrm{ml}\right)$. The conversion of the same cyano group to imino hydroxyl group 6 significantly decreased the potency to be less than the parent compound $\left(\mathrm{LC}_{50}: 52.1 \mu \mathrm{g} / \mathrm{ml}\right)$. While, the replacement of the cyano group with imidazole ring 19 intensified the potency to be the most active one of the tested derivative $\left(\mathrm{LC}_{50}: 35.5 \mu \mathrm{g} / \mathrm{ml}\right)$. Also, the replacement of 5-amino group of the pyrazole ring with imino ethoxy substituent 4 or the formation of the fused pyrimido-pyrazole ring system 12 ( $\mathrm{LC}_{50}$ : 55.9 and $74.5 \mu \mathrm{g} / \mathrm{ml}$ ) greatly inhibited the cytotoxic activity of the parent compound. Unfortunately, the rest of the examined compounds showed complete loss of activity.

In case of (HePG2) carcinoma cell lines, the data exhibited that six out of the ten tested derivatives exhibited cytotoxic activity. The attachment of imino ethoxy group to the pyrazole ring instead of the amino group 4 greatly increased the activity $\left(\mathrm{IC}_{50}: 30.8 \mu \mathrm{g} / \mathrm{ml}\right)$ to be more potent than the parent $3\left(\mathrm{LC}_{50}: 50.8\right.$ $\mu \mathrm{g} / \mathrm{ml})$. Also, an increase of the cytotoxic efficacy, but to a less extent, was observed due to the conversion of the cyano group to imino hydroxyl group 6 (LC $50: 45.3 \mu \mathrm{g} / \mathrm{ml})$ or imidazole ring $19\left(\mathrm{LC}_{50}: 40.7 \mu \mathrm{g} / \mathrm{ml}\right)$. A remarkable decrease in the activity was assigned due to the presence of the fused (substituted) pyrimido-pyrazole ring in conjugation with thiazolo-tetralin ring system as the derivatives 7 and $12\left(\mathrm{LC}_{50}: 69.9\right.$ and $\left.68.4 \mu \mathrm{g} / \mathrm{ml}\right)$, respectively.

With respect to the obtained data of MCF7 cell lines: it is observable that the number of the active derivatives was larger than the other two types of carcinoma cell lines. About seven compounds exhibited cytotoxic activity against breast carcinoma cell lines. As the above HePG2, compound 4 inhibited the cancerous cell lines at $\left(\mathrm{LC}_{50}: 30.7 \mu \mathrm{g} / \mathrm{ml}\right)$, which is greatly less than that of the parent compound 3 of $\left(\mathrm{LC}_{50}: 44.3 \mu \mathrm{g} / \mathrm{ml}\right)$. While the other derivatives $6,7,12,15 \mathrm{a}$ and 19 showed observable drops in the cytotoxic activity.

These variations in the cytotoxic activities due to variation in the types of the substituents conjugated to the pyrazolo-thiazolotetralin core should be taken in our considerations while designing and synthesizing novel anticancer agents of high efficiency and selectivity.

Acknowledgment : The authors express thanks to Bioassay-Cell Culture Laboratory; In vitro bioassays on human tumor cell lines for drug discovery National Research Centre, El-Tahrir St., Dokki, Cairo, Egypt for carrying out the

Egypt. J. Chem. 55, No.4 (2012) 
anticancer screening. Also, thanks to Dr. Mohamed Abdou Khedr, Faculty of pharmacy, Helwan University for molecular docking studies.

\section{References}

1 Ali, M.M. and Hassan, S.A., Int J Cancer Res 3, 103 (2007).

2 Tsuchiya, T., Takagi, Y. and Yamada, H., Bioorg Med Chem Lett, 10, 203 (2000).

3 Fathalla, O.M., Anwar, M.M, Haiba, M.E. and Nofal, S.M., Acta Pol Pharm - Drug Research, 66, 259 (2009).

4 Hara, H., Fujihashi, T., Sakata, T., Kaji, A. and Kaji, H., AIDS Res. Hum. Retroviruses 13, 695 (1997).

5 Stigliani, J.L., Boustie, J., Amoros, M., Montanha, J., Payard, M. and Girre, L., Pharm Pharmacol Commun 4, 65 (1998)

6 Ferreante, A., Auliera, J., Lewis, K. and Klibanov, A.M., Proc Natl Acad Sci USA 92, 7617 (1995).

7 Nabih, I., Zayed, A., Kamel, M.M. and Motawie, M.S., Egypt J. Chem 29, 101 (1986).

8 Hussain, R.A., Dicky, J. and Rosser, M.P., J. Nat. Prod. 58, 1515 (1995).

9 Chalina, E.G. and Chakarova, L., Eur J. Med Chem 33, 975 (1998).

10 Kamel, M.M. and Michael, J.M., Egypt J. Bilharziasis 10, 121 (1988).

11 Cimetiere, B., Dubuffet, T. and Muller, O., Bioorg Med Chem Lett 8, 1375 (1998).

12 Rogoo, Z., Skuza, G. and Klodzinska, A., Pol J Pharmacol 56, 519 (2004).

13 Kitamuraa, Y., Arakib, H., Shibatac, K., Gomitac, Y., Tanizakid, Y., Eur J. Pharmacol 481, 75 (2003).

14 Amin, K.M., El-Zahar, M.I., Anwar, M.M., Kamel, M.M. and Mohamed, M.H., Acta Pol Pharm - Drug Research, 66, 279 (2009).

15 Soliman, E.A., El-Zahar, M.I., El-Masry, A.H. and Gohar, R.S., Egypt J. Chem 51, 701 (2008).

16 Lawrence, W., Purohit, A. and Barry, A.V.L., J. Med Chem 41, 1068 (1998).

17 Sikkena, J. and Bont, J.A., Appl Environ Microbiol 59, 567 (1993).

18 Chan, D.C.M. and Anderson, A.C., Curr Med Chem 13, 377 (2006). 
19 Hawser, S., Lociuro, S. and Islam, K., Biochem Pharmacol, 71, 94 (2006).

20 Blakley, R.L., Dihydrofolate Reductase. In Folate and Pterines, R.L. Blakley, S.J. Benkovic, Eds; Wiley-Interscinence: New York 1, 191 (1984).

21 MacKenzie, R.E., Biogenesis and interconversion of Substituted Tetrahydrofolates. In Folates and Pterins Chemistry and Biochemistry, R. L. Blakley, S. J. Benkovic, Eds.; Wiley: New York 1, 255 (1984).

22 Assaraf, Y.G., Cancer Metastasis Rev 26, 153 (2007).

23 Matherly, L.H. and Hou, Z., Vitam Horm 79, 145 (2008).

24 Nikolaos, T., Clin Cancer Res 2, 227 (1996).

25 Trott, O. and Olson, A.J., J. Comput Chem 31, 455 (2010).

26 El-Zahar, M.I., Abd El-Karim, S.S. and Anwar, M.M., S Afr J. Chem., 62, 189 (2009).

27 Mosmann, T., J. Immunol Methods 65, 55 (1983).

28 Thabrew, M.I., Hughes, R.D. and McFarlane, I.G., J. Pharm Pharmacol. 49, 1132 (1997).

(Received 12/12/2012; accepted 31/12/2012) 


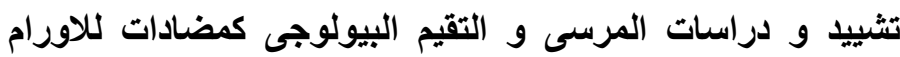 لبعض مشتقات رباعى هيدرونفثيل ثيازول بيرازول البولئ
}

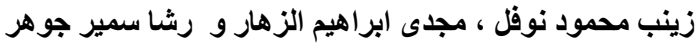

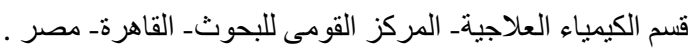

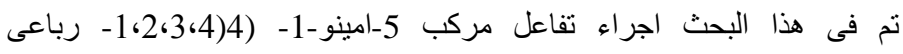

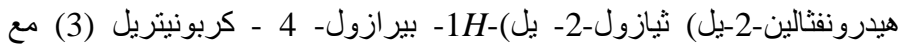

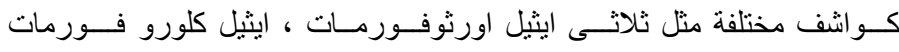

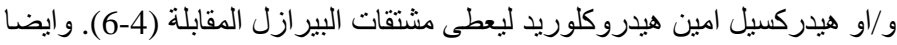

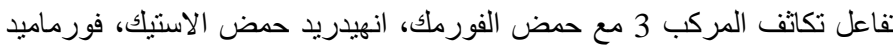

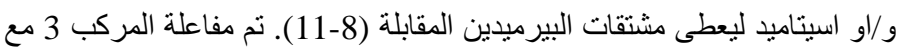

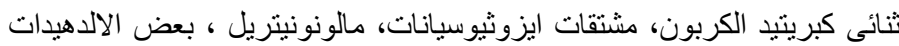

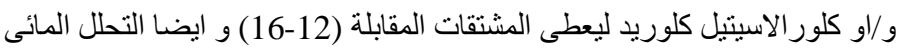
لمركب 3 بو اسطة حمض الكبرتيك تحت ظروف مختلفة اعطى مركبات 17، 18 18.

تم دراسة المرسى لهذه المركبات الجديـدة كمثبطات لانزيم ثيميديـلات

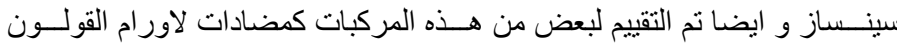

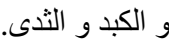

